\title{
A Multidisciplinary Health Strategic Approach for Sustainable Development: A Need for Developing Countries
}

\author{
Sophonie Ndahayo ${ }^{1 *}$ and Monique Mukanyandwi-Ndahayo ${ }^{2}$ \\ ${ }^{1}$ Associate Professor of Public Health, Texila American University, Zambia \\ ${ }^{2} \mathrm{HOD}$, Department of Natural Sciences, Rusangu University, Zambia \\ *Corresponding Author: Sophonie Ndahayo, Associate Professor of Public Health, Texila American University, Zambia.
}

Received: October 30, 2019; Published: November 12, 2019

DOI: 10.31080/ASNH.2019.03.0546

\begin{abstract}
In developing countries, there are risks of setback of the progress made in general development, and in the health sector in particular. Despite remarkable progress in many areas, poor health continues to be a constraint to sustainable development efforts. Global menace to health emanating from unhealthy food choices and physical inactivity contribute to an ever increasing prevalence of many diseases across all age-groups. For example, a projected increase in lifestyle-related diseases' burden represents one of the major challenges to future health development. Though non-communicable diseases, injuries and violence will account for nearly $80 \%$ of the global diseases burden in 2020 , observations show that many key determinants of health and diseases lie outside the direct control of the health sector. For sustainable development goals to be achieved, many stakeholders have each to play his/ her role: governments, Non-governmental organisations, academia, the private sector, and all people. Therefore, a multidisciplinary health approach is needed to prevent and control health threats among developing countries.
\end{abstract}

Keywords: Energy Drinks; Non-Communicable Diseases; Sustainable Development; Prevention

\section{Introduction}

During the $17^{\text {th }}$ United Nations General Assembly on September 25,2015 , world leaders come up with the concept of sustainable development. They dreamed of planet where each person's basic living needs are met. They thought of bringing about change in the way resources are allocate and distributed so that each if not many inhabitants of the world may enjoy freedom from hunger, unhealthy environment such as lack of education, violence, hunger, communicable and non-communicable diseases just to name a few.

Health is at the centre of the Sustainable Development Goals (SDGs) with the third that promotes to ascertain healthy lives and support a healthy well-being for all ages. However to accomplish involves action in key financial development aspects like accommodation, transport, as well as in other personal and community social economic situations. Obviously, accomplishment of the above described environment cannot be done by or through one person or institution. It requires input from many stakeholders who have health at heart. This is what is referred to as multidisciplinary approach where varied people and organisations will team up to bring about a healthy living environment. It further means that adults should make sure that children inherit a sustainable world. A safe, healthy and protective environment is the key to ensuring that children grow and develop normally. Children, especially the adolescents are in particular assailable to food and drinks advertisements which entice them to indulge in unhealthy eating and drinking, which may affect their health and endanger their role in sustainable development. While the health sector itself is changing to respond to many of its challenges, it can hardly address these problems alone. Many of the key determinants and solutions to health and disease lie outside the direct domain of the health sector, in multidisciplinary sectors concerned with among others: environment, water and sanitation, agriculture, education, employment, urban and rural livelihoods, trade, tourism, industrial development, energy and housing [1].

\section{Definition and application of sustainable development}

The most widely accepted definition of sustainable development refer to it is when humanity has the ability to make development sustainable - to ensure that it meets the needs of the present without compromising the ability of future generations to meet their own. For example, this adaptability allows strategies of environment or economic to each plan and project their activities and programmes towards promoting sustainable development. The use of this definition has led many players to see sustainable development as having a major focus on interpersonal equity [2].

Sustainable development requires the participation of various stakeholders and perspectives, with the idea of accommodating different and diverse or diverging values and goals toward a new synthesis and resulting coordination of mutually agreed actions to attain synergistic objectives. Achieving agreement on sustainabil- 
ity values, goals, and actions is often a hard and painful work, as different stakeholder values are affected, sometimes rejected. The situation may lead a number of concerned organisations or individuals to withhold their support or participation in projects that could benefit the population.

The above scenario happens, despite the fact that the health for all in the 21st century strategy adopted at the World Health Assembly in 1998 had chosen global priorities and targets which aim to ensure conditions for people worldwide to reach and maintain the highest attainable level of health throughout their lives. The strategy was and is still built on the principles of social justice, equity and human development, and emphasizes reduction of preventable diseases and health risks and promotion of population health. This was emphasized through the World Health Organization's corporate strategy which stated the goals of building healthy populations and communities and preventing diseases through the acceptation of four strategic approaches: reducing excess mortality, morbidity and disability, especially in poor and neglected populations groups; promoting healthy lifestyles and reducing underlying risk-factors; establishing, monitoring and evaluating health systems that equitably improve health outcomes; implementation of enabling policies that promote effective health dimensions. This means that for example, when one manufactures a product to sell and earn money and a living, the person should make sure that the product is not deleterious to the health of the consumer. Furthermore, the production and waste disposal should not harm the environment.

Yet, mounting evidences show that the food and drinks industry is engaged in products of which, some are not health-sustaining and development promoting. To understand why people are choosing to consume unhealthy commodities, it is necessary to study the nutrition transition and transformations to economic and social systems that are increasing availability and affordability of such products. Previous research has focused on the role played by urbanisation in the nutrition transition [3-6], but with the global rise of transnational food and drink companies there is a clear need to focus on the role of global producers in manufacturing and marketing the commodities implicated in non-communicable disease epidemics [7]. For instance, evidence-based findings have indicated that the rapid rise of non-communicable diseases has been threatening economic and social development as well as human lives and health of millions of people $[1,8]$. Their negative effects impact on low-and lower-middle- income nations remains a significant challenge. In all countries, the poorest and most vulnerable populations are those most at risk and the least likely to have access to the services they need to detect and treat non-communicable diseases.

It has been observed that unhealthy commodities are highly lucrative due to their low production cost, long shelf- life, and more retail profit. These marketing characteristics bring a lot of incentives for manufacturing industries to market and sell more of these commodities. To curb the negative health effects brought about by the above products requires efforts from more than one institution in any country. That is why this article advocates for a multidisciplinary health approach to achieve a sustainable development in Africa, where many health problems have reached epidemic levels. To illustrate the concept of health multidisciplinary strategic approach for sustainable development, we reviewed a research article entitled: A survey of energy- drinks consumption patterns among college Students by Malinauskas, B.M., Aeby, V.G., Overton, R.F., Carpenter-Aeby, T. and Barber, K. (2007) published in Nutrition Journal 6 (35), doi:10.1186/1475-2891-6-35.

Adolescents' energy needs vary depending on many factors that include: growth rate, gender, body composition and physical activity [9]. Energy comes from foods and drinks. Adolescents who take soft drinks regularly are more likely to be overweight $[10,11]$. Soft drinks containing caffeine present a different problem if caffeine intake becomes excessive $(200 \mathrm{mg})$. In greater amounts, caffeine has been associated with anxiety and other symptoms such as sweating, and inability to concentrate [12].

Harris and Munsell [13] found that the marketing of energy drinks is often youth-oriented and the energy drink market has grown rapidly in recent years with global consumption nearly doubling between 2006 and 2012 (Meier, 2012). However, there is a concern about the risks and potentially harmful effects of energy drinks consumption on consumers' health, especially young people, due to the high content of caffeine, sugar, and other ingredients such as taurine, guarana, vitamins, and herbal ingredients [13,14]. Some studies have detected correlations between energy drinks use and other risk-taking behaviours such as alcohol and drug use, smoking, sexual risk taking, and violence among adolescents and young adults $[15,16]$. Energy drinks, which include Red Bull, Amp, Monster, Rock Star, Rip It, Full Throttle, and Cocaine have the proprieties to give the consumer a boost of energy from a combination of stimulants and energy boosters among which the following are mentioned: caffeine, herbal extracts such as guarana, ginseng, and ginkgo biloba, B vitamins and amino acids such as taurine [17].

\section{Side effects of energy drinks}

The intake of energy drinks is contemporary regarded as a health-risk practice that is on an exponential rise globally [18]. Of great concern, especially to public health, is a seemingly lack of regulation for energy drinks mainly in terms of ingredients used in their manufacture. A lot of proof is emerging on the harmful physiological and psychological effects of energy drinks, which do not favour sustainable health and development. Rationally this would connote that prolonged consumption of these beverages may adversely affect ones' physical and mental well-being [19]. 


\section{Physical effects}

Among children and youth, regular energy drink consumption can cause dependence, even when energy drinks are consumed in moderate amounts [20]. In addition, risks observed from regular use of sugar sweetened beverages on individuals include noncommunicable diseases such as diabetes [21]. Other health consequences associated with the high sugar contents of the energy drinks include dental erosion and obesity. Nevertheless, upon consumption, experience of surge of energy followed by a rigid decrease in energy levels is experienced; this causes customers to turn to foods that are calorie - dense, which makes them vulnerable overweight and/ or and obesity and subsequent health effects [22]. Furthermore, results from some experimental studies found acute cardiovascular effects of energy drinks, especially among high-risk individuals [23].

Similarly, case reports have discovered an statistical associations between health effects such as: stroke, seizures, cardiac effects and energy drink consumption $[24,25]$. Associations between energy drinks consumption and high-risk behaviours such as alcohol consumption, sexual risk-taking practices, excitement of the desire and intention to drive under the influence of alcohol, as well as marijuana- use have also been reported [26].

In America, between 2004 and 2012, the United States Food and Drug Administration (USFDA) has also identified more than 30 deaths linked to energy drinks [27]. Even a study conducted in Finland found an increased odds of headaches were noted. In Australian a study among 12 to 18 year old, more than $50 \%$ of participants experienced at least one of the following symptoms after taking energy drinks: tachycardia, upset stomach, anxiety, tremors and heart palpitations.

\section{Psychological effects}

Results of a study conducted in Italy revealed that $45 \%$ of medical students reported lack of sleep and irritability following energy drink intakes. Population-based studies are believed to give clearer and more realistic reports, because contacts are more proactive. In one school-based study, sleeping problems and irritability were notable among energy drink users [28]. The contemporary market environment places various burdens on youths and adult as well. They find themselves overcome by some unanticipated events of life. In a seeking to carry out many daily activities, which require more energy, some people get tempted to rely on some external drives and source of energy. Appeals from claims of energy drink manufacturers and advertisements, which seem to meet their present energy need, a sizeable number of individuals fall prey to energy drink consumption. Such a predicament is not surprising because a boost of one's energy levels, increased physical endurance, as well as a shorter reaction rate and increased mental concentration are every individual's desires. Having identified these needs, energy drink manufacturers market their products as the solution to the desperate individuals' need [29]. The widespread trend of an exponential increase in the consumption of energy drinks leaves African countries as no exception. This unacceptable plight is worsened by a regulatory oversight, coupled to an aggressive marketing by the industry towards the youths [30]. There is a great need for critical evaluation of the nutritional content of energy drinks, even more of their adverse effects on the human body, especially that the target group for the energy drink industry are adolescents and young adults [31-37].

The above information is just a glimpse of the underlying health effects of energy drinks consumption. Nevertheless, considering the variety of their brands, manufactured quantities, marketing strategies, consumption of energy drink products and their medium and long-term effects, it becomes evident that sustainable development advocates have to use a multidisciplinary approach to mitigate the effects of energy drinks consumption.

In conclusion, to meets the needs of the present without compromising the ability (health) of future generations to meet their own, an example of a multidisciplinary health approach for a sustainable development in line of energy drinks can be achieved through the following just to name a few:

- Parents: To be educated and urged to pass the knowledge to down generations about the side health effects of energydrinks.

- Educators: Raise awareness about the need for consumers to read food labels and interpret the information.

- Soft drinks manufacturers: To clearly label all their products and include known health side effects. Furthermore, they should abide by all government regulations.

- Research scientists: More research in the area of childhood origins of adult diseases. Scientists to carry out more research in line with foods and drinks composition and underlying health side effects.

- Agriculture sector: To produce more fruits to increase manufacture of natural fruit juices.

- Law-makers: To enact laws, if not available, to regulate production and sale of energy drinks.

- Government (Ministry of Commerce trades and industry in conjunction with the Ministry of health and other stakeholders) to increase monitoring and control systems in the manufacture and trade of foods and drinks produced or imported through regulations enactment if they are not there, or implementation.

- Media (printed, visual, social etc...) to put more efforts in consumer education even in terms of health side effects of energy drinks.

\section{Bibliography}

1. WHO. "Health and sustainable development: addressing the issues and challenges" (2002).

2. Kates RW., et al. "What is sustainable development? Goals, indicators, values and practice". Environment: Science and Policy for Sustainable Development 47.3 (2005): 8-21. 
3. Popkin B. "Urbanization, lifestyle changes, and the nutrition transition”. World Development 27 (1999): 1905-1916.

4. Chow C., et al. "Environmental and societal influences acting on cardiovascular risk factors and disease at a population level: a review". International Journal of Epidemiology 38 (2009): 1580-1594.

5. Subramanian S and Davey SG. "Patterns, distribution and determinants of under and over-nutrition: a population based study of women in India". American Journal of Clinical Nutrition 84 (2006): 633-640.

6. Agyemang C., et al. "Blood pressure patterns in rural, semi-urban and urban children in the Ashanti region of Ghana, West Africa." BMC Public Health 5 (2005): 114.

7. Stuckler, D., et al. "Manufacturing epidemics: the role of global producers in increasing consumption of unhealthy commodities including processed foods, alcohol and tobacco". PloS Medicine 9 (2012): e1001235.

8. Non-communicable diseases country profiles. Geneva: World Health Organisation (2018).

9. Institute of Medicine. "Dietary Reference Intakes for Energy, Carbohydrate, Fiber, Fat, Fatty Acids, Cholesterol, Protein, and Amino Acids". Washington, DC: The National Academies Press (2005).

10. Vartanian RL., et al. "Effects of Soft Drink Consumption on Nutrition and Health: A Systematic Review and Meta-Analysis". American Journal of Public Health 97.4 (2007): 667-675.

11. Malik VS., et al. "Intake of sugar-sweetened beverages and weight gain: a systematic review". The American Journal of Clinical Nutrition 84.2 (2006): 274-288.

12. Rolfes SR., et al. "Understanding normal and clinical nutrition 9th Edition". California: Wadsworth (2012).

13. Harris JL and Munsell CR. "Energy drinks and adolescents: what's the harm?" Nutrition Reviews 73.4 (2015): 247-257.

14. Pomeranz JL., et al. "Energy drinks: an emerging public health hazard for youth". Journal of Public Health Policy 34.2 (2003): 254-271.

15. Azagba S., et al. "An emerging adolescent health risk: caffeinated energy drink consumption patterns among high school students". Preventive Medicine 62 (2014): 54-59.

16. Miller KE. "Energy drinks, race and problem behaviours among College Students". Journal of Adolescent Health 43.5 (2008): 490-497.

17. Boyle M and Castillo VD. "Monster on the loose". Fortune 154 (2006): 116-122.

18. Pettit ML and DeBarr KA. "Perceived stress, energy drink consumption, and academic performance among college students". Journal of American College Health 59.5 (2011): 335341.
19. Ishak WW., et al. "Energy drinks: psychological effects and impact on well-being and quality of life-a literature review". Innovations in Clinical Neuroscience 9.1 (2012): 25-34.

20. Smithers R. "Call for ban on selling 'addictive' energy drinks to children". The Guardian (2015).

21. Malik VS., et al. "Sugar -sweetened beverages and risk pf metabolic syndrome and type 2 diabetes: a meta-analysis". Diabetes Care.

22. Ledikwe JH., et al. "Dietary energy density is associated with energy intake and weight status in US adults". American Journal of Clinical Nutrition 83.6 (2006): 1362-1368.

23. Svatikova A., et al. "A randomized Trial pf Cardiovascular Responses to Energy Drink Consumption in Healthy Adults". Journal of the American Medical Association 314.19 (2015): 2079-2082.

24. Dikici S., et al. "Do energy drinks cause epileptic seizure and ischemic stroke?". American Journal of Emergence Medicine 31.1 (2013): 274.e1-4.

25. Ferlazzo E and Aguglia U. "Energy drinks and seizures: What is the link?” Epilepsy and Behaviour 24.1 (2012): 151.

26. Velazquez CE., et al. "Association between energy drink consumption and alcohol use behaviours among college students". Drug and Alcohol Dependence 1123.1-30 (2012): 167-172.

27. United States Food and Drug Administration. "Adverse event reports allegedly related to Red Bull". Silver Spring (MD).

28. Huhtinen H., et al. "Adolescents' use of energy drinks and caffeine induced health complaints in Finland: ArjaRimpela". European Journal of Public Health 23.1 (2013).

29. Van den Eynde F., et al. "The effects of energy drinks on cognitive performance [Article in Dutch]". Tijdschrift voor Psychiatrie 50 (2008): 273-81.

30. Reissig CJ., et al. "Caffeinated Energy Drinks -- A Growing Problem". Drug and Alcohol Dependence 99.1-3 (2009): 1-10.

31. Heckman MA., et al. "Energy drinks: An assessment of their market size, consumer demographics, ingredient profile, functionality, and regulations in the United States". Comprehensive Review in Food Science and Food Safety 9.3 (2010): 303-317.

32. National Research Council, Policy Division, Board on Sustainable Development, Our Common Journey: A Transition toward Sustainability (Washington, DC: National Academy Press (1999): 22.

33. Utter J., et al. "Energy drink consumption among New Zealand adolescents: Associations with mental health, health risk behavioural and body size". Journal Paediatrics and Child Health 54.3 (2018): 279-283.

34. Higgins JP., et al. "Energy Beverages: Content and Safety”. Mayo Clinic Proceedings 85.11 (2010): 1033-1041. 
35. Takian A and Akibari-Sari A. "Sustainable Health Development Becoming Agenda for Public Health Academia”. Iran Journal of Public Health 45 (2016): 1502-1506.

36. WHO. Global strategy on diet, physical activity and health.

37. WHO. Global action plan for the prevention and control of non-communicable diseases 2013-2020.

\section{Volume 3 Issue 12 December 2019}

(C) All rights are reserved by Sophonie Ndahayo., et al. 